\title{
Performance of an innovative gravity-driven micro-filtration technology for roof rainwater treatment
}

\author{
Chen Shiguang ${ }^{\dagger}$, Sun Hongwei, Chen Qiuli \\ College of Urban and Rural Construction, Zhongkai University of Agriculture and Engineering, Guangzhou 510225, China
}

\begin{abstract}
Rainwater harvesting has become an important strategy to achieve the goal of sustainable development in urban areas. The latest emerged gravity driven micro-filtration technology can effectively reduce turbidity and bacteria to a very low level but still have disadvantages of low removal of dissolved organic substances and low permeate flux. An innovative gravity driven micro-filtration technique using ceramic flat sheet membrane as filter module was established and introduced to the treatment of rainwater that was harvested from a typical official building in GuangZhou, South China. The performance of this process has been evaluated in terms of pollutants (e.g. pH, turbidity, total dissolved solids (TDS), CODcr, $\mathrm{NH}_{3}-\mathrm{N}$, DOC,UV254, total Coliforms and E.coli) removal efficiency, and the permeate flux profiles. Results shows that the removal rates of turbidity, TDS, CODcr, $\mathrm{NH}_{3}-\mathrm{N}$, DOC,UV254, Coliforms and E.coli were 92.2\%, 91.9\%, 65.5\%, 42.6\%, 76.9\%, 61\%, 96.9\% and 95.5\%, respectively. The GDM system can run continuously for 60 days without back washing, and the permeate flux stabilized at $22 \sim 45 \mathrm{~L} /\left(\mathrm{m}^{2} \cdot \mathrm{h}\right) \mathrm{under}$ a constant water head of $20 \mathrm{kPa}$. Experimental results demonstrated that the GDM system employing a ceramic flat membrane can significantly improve the organics removal in rainwater.
\end{abstract}

Keywords: Ceramic membrane, Harvesting, Micro-filtration, Rainwater

\section{Introduction}

Most urban areas around the world have witnessed rapid population growth and are confronted with the issue of supplying adequate water to satisfy the demand of social consumption and economic activities [1]. Rainwater and stormwater recycling offer promising alternatives to address water supply pressures in areas where water sources are scarce or polluted [2]. The reuse of rainwater enables a reduction in the consumption of potable water, thus saving fresh water resources, reduce energy intensity,diminishing stormwater runoff and combined sewer overflows [3-6].

Nevertheless, until recently, widespread implementation of rainwater harvesting systems in urban areas have not yet emerged [7]. Public health concern is considered to be one of the main obstacles for rainwater and stormwater reuse [8]. Although rainwater is generally of a high quality(COD $<200$ $\mathrm{mg} / \mathrm{L})$, rainwater in the urban area still contains a certain amount of contaminants including particles, microorganisms and organics [9]. Therefore, further treatment of the collected rainwater is necessary for the supply of safe and sanitary water for potable

This is an Open Access article distributed under the term of the Creative Commons Attribution Non-Commercial License (http://creativecommons.org/licenses/by-nc/3.0/) which permits unrestricted non-commercial use, distribution, and reproduction in any medium, provided the original work is properly cited.

Copyright (C) 2021 Korean Society of Environmental Engineers or non-potable use. Various methods of treating rainwater for the non-portable use have been widely adopted, such as chlorination, pasteurization by solar technology, biofiltration, membrane separation, etc $[10,11]$.

Emerged as a low energy consumption and chemical free technology, the gravity driven membrane (GDM) filtration process is receiving more attentions and has been introduced to treat rainwater prior to use [12-14]. Although the GDM process has demonstrated an excellent performance in removing the bacteria and suspended particles in surface water and wastewater treatment, however, this energy-saving technology still has some disadvantages, such as, the removal of low molecular-weight substances is not ideal [15]. Thus, new technologies targeting to improve the dissolved organic matter removal in GDM systems need to be explored.

In the design of GDM filtration process, the selection of filter media is of critical importance, as is related to the removal efficiency of pollutants, initial costs and permeate fluxes [16]. As a new filter material, micro-porous ceramic has lower density and higher specific surface area as compared to conventional micro-filtration membrane media such as cellulose acetate, polyvinylidene fluoride

\footnotetext{
${ }^{\dagger}$ Corresponding author

Email: luyi813929@163.com

Tel: +86-20-89002673 Fax: +86-20-89002673

ORCID: 0000-0002-4102-6886
} 
(PVDF), and polyethersulfone (PES) [17]. The ceramic filter has been reported to satisfactorily remove different pollutants in drinking water treatment, i.e., $40-58 \%$ for TOC and more than $70 \%$ for nitrogen $[18,19]$. These signify that employing ceramic membrane is very likely to achieve the desired results in rainwater treatment which has not been reported to date.

Most previous studies on GDM technologies have focused on the organic hollow fibre membranes probably linked to the hypothesis that a higher packing density of the membrane module is assumed to achieve more productivity per unit of footprint [20]. However, it is noted that, compared to the hollow fibre membrane modules, the flat sheet membrane modules, can offer superior environment for the growth, movement and predation behaviour of eukaryotic in the bio-fouling layer, which is responsible for the reduction of bio-fouling layers on the membrane, (i.e., form an open, heterogeneous, and porous fouling layer), and consequently contribute to a relatively higher level of permeate flux. Moreover, since previous studies have stated that membrane fouling was primarily due to the deposition of soluble microbial products such as polysaccharides, proteins, and fulvic substances onto the membrane surface [21, 22], the ceramic membrane, which possesses properties of higher hydrophilic, thus has the potential to prevent the formation of cake layer (because hydrophilic membrane can effectively prevent those substances from migrating to the membrane surface). Such characteristic offers a possibility to improve the overall permeate flux of GDM system.

Nevertheless, whether a flat sheet ceramic membrane can benefit to improve the removal efficiency of DOC or to enhance the productivity of the GDM systems for rainwater treatment is to date not been reported. Therefore, the objective of this study is to assess the performance of ceramic flat membrane in rainwater filtration. An innovative GDM filtration system using ceramic flat membrane as filter module was designed and used for the rainwater treatment in an official building located in Guangzhou, South China. The pollutants removal efficiency was investigated in terms of $\mathrm{pH}$, turbidity, total dissolved solids (TDS), CODcr, $\mathrm{NH}_{3}-\mathrm{N}$, DOC,UV254, total Coliforms and E.coli, and the impacts of flat sheet membrane on GDM permeate flux development were also evaluated. It should be point out that, the current work is specific to study site, the results obtained may vary from one location to another due to the the quality of rainwater depends on rainfall amount, the type of roof and storage material adopted etc.

\section{Material and Methods}

This section presents the study site, the materials used, the description of the RWH system, the GDM process, and the analytical methods employed in this study.

\subsection{Study site}

The study site (with latitude $23^{\circ} 37^{\prime}$ north and longitude $113^{\circ} 44^{\prime}$ east), locates on the North edge of the Pearl River Delta (PRD) Plain in the province of Guangdong in southern China, which, according to the classification, has a typical subtropical monsoon climate, and the average annual precipitation is around $1,790 \mathrm{~mm}$ (statistical average from 1980s 2010s). The average annual temperature is $22.5^{\circ} \mathrm{C}$ with no frost or snowfall. The location map of study site is presented in the supplementary materials (named Fig. S1).

\subsection{Materials}

The raw-rainwater used in this study was harvested from a planted roof of an eight-story multi-functional building (with catchment area of $1,122 \mathrm{~m}^{2}$ ). The GDM device was designed and manufactured by Shen Zhen Jingrui 3D Printing Co.,Ltd (Shenzhen, China). Flat-sheet ceramic membranes with multi-channels (ZhongQing Environmental Technology Co.,Ltd, Shenzhen, China) were used in this study. They are made from alpha-alumina with a nominal pore size of $0.1 \mu \mathrm{m}$. Each membrane has a dimension of $520 \times$ $200 \times 4 \mathrm{~mm}(\mathrm{~L} \times \mathrm{W} \times \mathrm{H})$ corresponding to a filtration area of $0.21 \mathrm{~m}^{2}$ (double side inlet). The flat sheet ceramic membrane has the characteristics of high structural strength, excellent durableness (it can operate under extremely harsh conditions such as strong acid, strong alkali and high temperature), and low maintenance costs due to no backwashing and chemical cleaning.

\subsection{RWH Systems}

The RWH system consists of four main elements: (1) Catchment surface: Rooftop $\left(1,122 \mathrm{~m}^{2}\right)$. (2) Storage facilities: A raw-rainwater tank installed below roof, and an effluent tank (Fig. 2) to temporary store water before use. (3) The gravity driven micro-filtration treatment unit. (4) Delivery system: Set of pipes that transport rainwater from the catchment area to the storage tank and then from the storage tank to effluent tank and ultimately sent to the end users of the building. The treated rainwater was mainly used for toilet flushing, hand washing and laundry. The schematic diagram of RWH system can be found in supplementary materials (named Fig. S2).

\subsection{Process Operation}

The schematic view of the GDM reactor is shown in Fig. 1. Before filtration, harvested rainwater was temporary stored in a raw rainwater tank. Excesses of rainwater were discharged by gravity drainage through overflow pipe when the collected rainwater exceeded the capacity of the storage tank, while a float valve was used to ensure that the level of rainwater inside the tank does not go below a certain threshold level during periods without rainfall (Fig. 1).

The rainwater was first screened with a $0.55 \mathrm{~mm}$ sieve to remove large suspended particles, then fed into the membrane tank at a controlled rate that synchronised with the filtrates withdrawal. A $20 \mathrm{kPa}(2 \mathrm{~m})$ gravitational head generated from the height between the raw-rainwater tank and the effluent tank was utilized to drive the rainwater flow though the membrane filter (Fig. 1). After filtration, the treated rainwater was temporary stored in the effluent tank for distribution. The GDM system operated in a dead-end filtration mode, and the running duration of the system was 60 days (from June 12 to August 14, 2019) with a primarily flux of $168 \mathrm{~L} / \mathrm{m}^{2} \cdot \mathrm{h}$. The average hydraulic retention time (HRT, which is calculated by dividing reactor volume by permeate flow rate) in the membrane tank was $7.63 \mathrm{~h}$. 


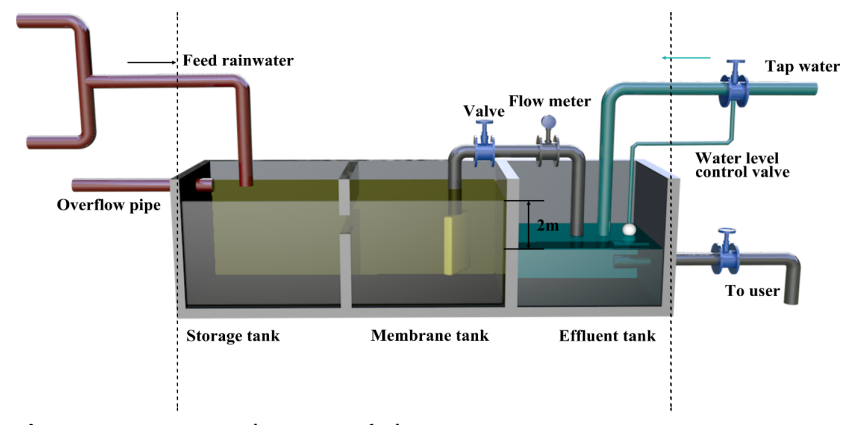

Fig. 1. Experimental setup of the GDM unit.

\subsection{Analytical Methods}

During the experiments, samples obtained from the feed tank, and effluent tank were analyzed regularly for $\mathrm{pH}$, total dissolved solids (TDS), turbidity, ammonia nitrogen $\left(\mathrm{NH}_{3}-\mathrm{N}\right)$,chemical oxygen demand (CODcr), dissolved organic carbon (DOC), UV254. For microbiological parameter all samples were examined for the two widely used bacterial indicators, total Coliforms, and Escherichia coliform. The $\mathrm{pH}$ was determined by a Phs-3c precision $\mathrm{pH}$ meter (Rex Electric Chemical, China), and the turbidity was measured using a $2100 \mathrm{P}$ Portable Turbidity meter (HACH,USA). TDS was determined by gravimetric method according to the Standard Methods for Examination of Water and Wastewater [23]. DOC was measured by using the Multi N/C 2000 analyzer (Analytik Jena AG). CODcr was determined by a DR-1010 COD rapid Monitor (HACH, USA) and $\mathrm{NH}_{3}-\mathrm{N}$ was measured using a 722 spectrophotometer (Shimadzu, Japan), while UV254 was monitored by an uv-2450 ultraviolet spectrophotometer (Shimadzu, Japan) in terms of UV absorbance at the wavelength of $254 \mathrm{~nm}$. For Total Coliforms and E. coli analyses the methods outlined in APHA (2005) were adopted. Acetate cellulose filters ( $0.45 \mu \mathrm{m}$ poresize, Biocomma, China) were used for sample filtration while m-Endo Broth medium (Shanghai binsui Biotechnology Co., Ltd, China) and Tryptone Bile X-Glucuronide (TBX) medium (Shanghai Zeye Biotechnology Co., Ltd, China) were employed respectively for Coliform and E.coli retention. The results were expressed in terms of colony forming units per $100 \mathrm{~mL}(\mathrm{CFU} / 100 \mathrm{~mL})$. The measurement frequencies for $\mathrm{pH}$, turbidity, TDS, CODcr, $\mathrm{NH}_{3}-\mathrm{N}$, UV254, dissolved organic carbon (DOC) were once a day, while for Coliform and E.coli were once every three days. The measurements were made thrice each time.

A PZ-M digital camera of biological microscope (Shanghai Optical Instrument Factory,China) was used as an in situ method to capture the morphologies of microorganisms on the membrane surface of the GDM reactor. These measurements were conducted on the first day, the 20th day, the 40th day and the 60th day of the experiment.

\section{Results}

Laboratory experiments monitored the daily water quality and flux decline from the GDM filter system. The following sections report representative results obtained during 60 days experiment.

\subsection{Analysis of Effluents Quality}

Table 1 compares the quality of influent rainwater and effluent from GDM system. All parameters monitored in this experiment are compared against the limits of Chinese Recycling Water Guidelines (CRWG,2014) [24] and Chinese Drinking Water Guidelines (CDWG,2006) [25], respectively.

The results showed that the rainwater collected in study site generally complied with the limits of CRWG (2014) except for parameters such as the turbidity, CODcr, and bacteria (Table 1). This may due to the fact that the sampling site is far away from the urban area and less polluted by automobile exhaust or industrial emissions.

As shown in Table 1, the $\mathrm{pH}$ value of feed rainwater ranged from 6.4 to 8.1 , with an average value of 7.4 , and the $\mathrm{pH}$ range of effluent from GDM reactor was 6.7-8.3 over the entire experimental period. The effluent $\mathrm{pH}$ value were in compliance with the CRWG (2014) and CDWG (2006), in which the permissible limit for $\mathrm{pH}$ should be in the range of 6.5-9.0 and 6.5-8.5, respectively.

During the experiments, the turbidity in the raw rainwater ranged from 4.22 to $7.50 \mathrm{NTU}$ (or $5.86 \pm 1.64$ NTU on average, as shown in Tab.1). The CRWG (2014) has a recommended limit for turbidity of 5 NTU, therefore the raw rainwater concentration of turbidity was in most cases beyond the CRWG limit. The gravity driven

Table 1. Rainwater and GDM Effluent Quality

\begin{tabular}{|c|c|c|c|c|}
\hline Analytical Parameters & Feed Rainwater & GDM Effluent & CRWG limit & CDWG limit \\
\hline Turbidity (NTU) & $5.86 \pm 1.64$ & $0.46 \pm 0.33$ & 5 & 1 \\
\hline DOC (mg/L) & $9.4 \pm 3.86$ & $2.17 \pm 0.51$ & - & 5 \\
\hline $\mathrm{pH}$ & $7.4 \pm 0.7$ & $6.7 \sim 8.3$ & $6.5 \sim 9$ & $6.5 \sim 8.5$ \\
\hline TDS (mg/L) & $209 \pm 172.4$ & $17 \pm 10.3$ & 1,000 & 1,000 \\
\hline CODcr (mg/L) & 35. $9 \pm 15.6$ & $12.4 \pm 4.4$ & 50 & 5 \\
\hline $\mathrm{NH}_{3}-\mathrm{N}$ & $5.59 \pm 2.89$ & $3.21 \pm 1.56$ & 10 & 0.5 \\
\hline UV254 $\left(\mathrm{cm}^{-1}\right)$ & $0.087 \pm 0.024$ & $0.034 \pm 0.018$ & - & 0.060 \\
\hline E. coli $(\mathrm{CFU} / 100 \mathrm{~mL})$ & $330 \pm 142$ & $0 \sim 30$ & $\leq 100$ & $\mathrm{ND}$ \\
\hline Coliforms (CFU/100 mL) & $128 \pm 37$ & $0 \sim 9$ & $\leq 100$ & ND \\
\hline
\end{tabular}

Note: ND represents "not detectable" 
micro-filtration (GDM) system, reduced the turbidity by an average of $92.2 \%$, to a levels of $0.46 \pm 0.33$ NTU, with the effluent turbidity well complied with the Chinese Drinking Water Guidelines (2006), which prescribed the turbidity $<1.0 \mathrm{mg} / \mathrm{L}$. The low effluent turbidity from GDM reactor was expected due to the filtration function of ceramic membrane that with pore size of $0.1 \mu \mathrm{m}$. Since most of the suspended particles in rainwater were more than $0.1 \mu \mathrm{m}$ in diameter, therefore, negligible amount of turbidity related pollutants can penetrate ceramic membrane of the GDM reactor.

Table 1 also compares the TDS concentration of feed rainwater and effluent from GDM unit. The TDS in the stored rainwater fluctuated between 33.6 and $384.4 \mathrm{mg} / \mathrm{L}$, while the effluent TDS ranged from 6.7 to $27.3 \mathrm{mg} / \mathrm{L}$, much lower than the limit of the Chinese Drinking Water Guidelines $(<1,000 \mathrm{mg} / \mathrm{L})$. The TDS removal was mostly above $90 \%$ with an average removal rate of 91.9\% over the experiment period.

Two bacterial indicators, total Coliform and E. coli were detected to reflect the microbiological variables of rainwater. The feed rainwater contains total Coliforms an average value of $128 \mathrm{CFU} / 100 \mathrm{~mL}$ within a range of 91 to $165 \mathrm{CFU} / 100 \mathrm{~mL}$, and contains E.coli an average value of $330 \mathrm{CFU} / 100 \mathrm{~mL}$ within a range of 188 to 472 CFU/100 mL (Table 1). In current study, the influent Coliforms and E.coli concentrations in rainwater were somewhat lower than the reported range of previously literatures (i.e. typically 10-12,000 CFU/100 mL for coliforms and 0-3,200 CFU/100 mL for E.coli, respectively [26]. This probably linked to the seasonal fluctuations of microbiological parameters which were affected mainly by the cleanness level of catchment areas. In GDM effluent, the Coliform concentrations were ranged from 0 to $9 \mathrm{CFU} / 100 \mathrm{~mL}$, and the E.coli were ranged from $0 \sim 30 \mathrm{CFU} / 100 \mathrm{~mL}$ (seen Table 1), approximately $95 \%$ of bacteria in the rainwater were removed. Whereas the CDWG (2006) suggests non-detectable Coliform and E.coli per $100 \mathrm{~mL}$, while CRWG (2014) suggests no more than 100 Coliform and E.coli per $100 \mathrm{~mL}$, therefore the bacteria concentration in the treated water well satisfy the non-potable water standard and in most cases meets the drinking water standard.

According to the results, in GDM reactor, the effluent concentrations of $\mathrm{NH}_{3}-\mathrm{N}$ were $3.21 \pm 1.56 \mathrm{mg} / \mathrm{L}$, the effluent CODcr were ranged from 8.0 to $16.8 \mathrm{mg} / \mathrm{L}$, whereas the effluent DOC were between 1.66 and $2.68 \mathrm{mg} / \mathrm{L}$, the effluent UV254 of rainwater were $0.034 \pm 0.018 \mathrm{~cm}^{-1}$. The rejection of $\mathrm{NH}_{3}-\mathrm{N}$, and UV254 by the $0.1 \mu \mathrm{m}$ ceramic membrane was $42.6 \%$ and $61 \%$, and the removal of CODcr and DOC were $65.5 \%$ and 76.95 , respectively, which were far less than those of turbidity, TDS, and bacteria, the latter have demonstrated a rejection of $92.2 \%, 91.9 \%$ and $95 \%$, respectively. The diversity of particle size could be responsible for the difference in removal efficiencies among various physicochemical parameters.

As known to remove contaminants mainly through filtration, the GDM system has its removal efficiency generally increases with decreasing nominal pore size of membranes. Theoretically, the pollutants with diameter less than $0.1 \mu \mathrm{m}$ cannot be rejected through micro-filtration process. Since the sizes of dissolved organic matters are generally less than 100nm in diameter [27], therefore, majority percentage of these small molecule contaminants would not be rejected by GDM system. However, it was observed that there were still more than half of $\mathrm{NH}_{3}-\mathrm{N}$, CODcr and DOC in rainwater were removed by ceramic membrane in current GDM filtration system, this hinted that some supplementary mechanisms occurred during the filtration process.

\section{2. $\mathrm{NH}_{3}-\mathrm{N}$ and Organics Removal}

Fig. 2 illustrated detailed $\mathrm{NH}_{3}-\mathrm{N}$ concentrations of the feed rainwater and effluent from GDM system during the experimental period. The average $\mathrm{NH}_{3}-\mathrm{N}$ concentration of the effluent throughout the experimental period was $3.21 \mathrm{mg} / \mathrm{L}$, corresponded an average removal rate of $42.6 \%$, with the effluent quality well below the Chinese Recycling Water Guidelines limit of $10 \mathrm{mg} / \mathrm{L}$, but beyond the Chinese Drinking Water Guidelines limit of $0.5 \mathrm{mg} / \mathrm{L}$. As can be seen from Fig. 2, it was obviously that the removal efficiency of ammonia nitrogen by GDM system seem to be slightly higher in the later period of operation, e.g., the effluent concentrations of $\mathrm{NH}_{3}-\mathrm{N}$ were fluctuated between $2.53 \sim 4.77 \mathrm{mg} / \mathrm{L}$ in the first 30 days, corresponding to average removal rate of $33.6 \%$, and ranged of 3.32 to 4.63 $\mathrm{mg} / \mathrm{L}$ from day 31 to day 46 , corresponding to average removal rate of $44.3 \%$, while over the final 14 days of the experiment, the effluent $\mathrm{NH}_{3}-\mathrm{N}$ concentrations were in the range of 1.65 3.22 $\mathrm{mg} / \mathrm{L}$, corresponded an average removal rate of $57 \%$.

Fig. 3 compares the CODcr concentrations in feed rainwater and filtrates from GDM reactor. It can be seen from Table 1 that chemical oxygen demand (CODcr) in raw rainwater were 35.9 \pm 15.6 $\mathrm{mg} / \mathrm{L}$, with maximum value exceeded the recommended limit $(<$ $50 \mathrm{mg} / \mathrm{L}$ ) of Chinese Recycling Water Guidelines. As shown in Fig. 3, a great part of CODcr in the raw rainwater was removed after GDM treatment that achieved an effluent CODcr between 8 16.8 mg/L, well below the Recycling Water limits but slightly exceeded the standards for drinking water quality, contributed an average reduction of $65.5 \%$. Nevertheless, previous studies have reported that the organic matters cannot be effectively removed by micro-filtration process, as stated by Ding et al. [15], the removal rate of organic matter by micro-filtration process was lower than $20 \%$, this discrepancy with current study may be attributable to the differences in properties of membrane adopted. Our observations

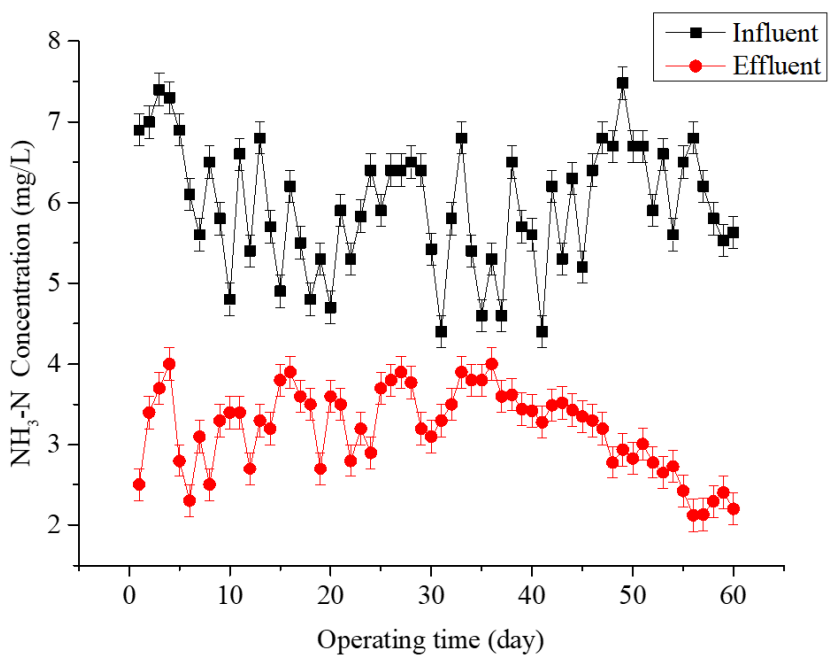

Fig. 2. $\mathrm{NH}_{3}-\mathrm{N}$ removal of the GDM unit during operation period. 


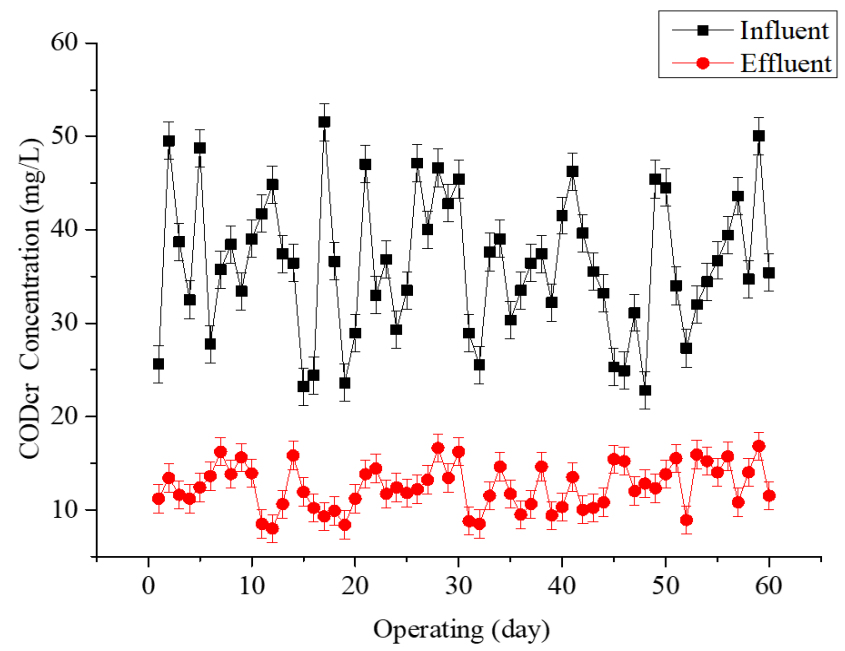

Fig. 3. CODcr removal of the GDM unit during operation period.

demonstrated that in case of rainwater treatment, the GDM process using ceramic membranes enables a considerable reduction in these pollutants that cause CODcr. Presumably this may linked to the biological process that occurred on the ceramic membrane surface due to the formation of a bio-film as the experiment were prolonged.

Fig. 4 and Fig. 5 illustrate the comparison of influent and effluent rainwater from GDM system in term of water quality parameters of DOC and UV254, respectively. As listed in Table 1, the influent rainwater samples contained an average dissolved organic carbon (DOC) of $9.4 \pm 3.86 \mathrm{mg} / \mathrm{L}$. According to Fig. 4, the GDM system removed majority of the dissolved organics matters that gave a final effluent DOC concentrations of $2.17 \pm 0.51 \mathrm{mg} / \mathrm{L}$ or $76.9 \%$ removal efficiency. The influent rainwater samples contained UV254 a range of $0.087 \pm 0.024 \mathrm{~cm}^{-1}$, and the GDM treatment reduced the UV254 to a level of $0.034 \pm 0.018 \mathrm{~cm}^{-1}$, which resulted in a greater than $61 \%$ reduction. Therefore, it can be concluded that great parts of DOC and UV254 were removed from feed rainwater through this GDM system. As for the micro-filtration processes, the effects are usually associated with the pore size of the membrane, whereas the nominal pore size of the micro-filtration membrane $(0.1 \mu \mathrm{m})$ is far greater than those of dissolved organic matters, therefore most of the dissolved organic matters that cause DOC and UV254 in the rainwater cannot be rejected by alone micro-membrane. It is assumed that the removal of dissolved organic matters may be on one side imputable to the adsorption by porous ceramic membrane, and on the other hand linked to the flat sheet membrane that can offers a desirable surface for the attachment of microbial communities, which can also help to reduce the DOC contents through bio-degradation.

As can be seen from Fig. 4, the effluent concentrations of DOC were found lower in later stage of experimental operation. These observations were well in agreement with the aforementioned hypothesis that the removal of dissolved organic matters was resulted from the conjoint effects of adsorption by ceramic membrane and degradation by the bio-film on the membrane surface (detailed reasons will be presented in the section of discussion).

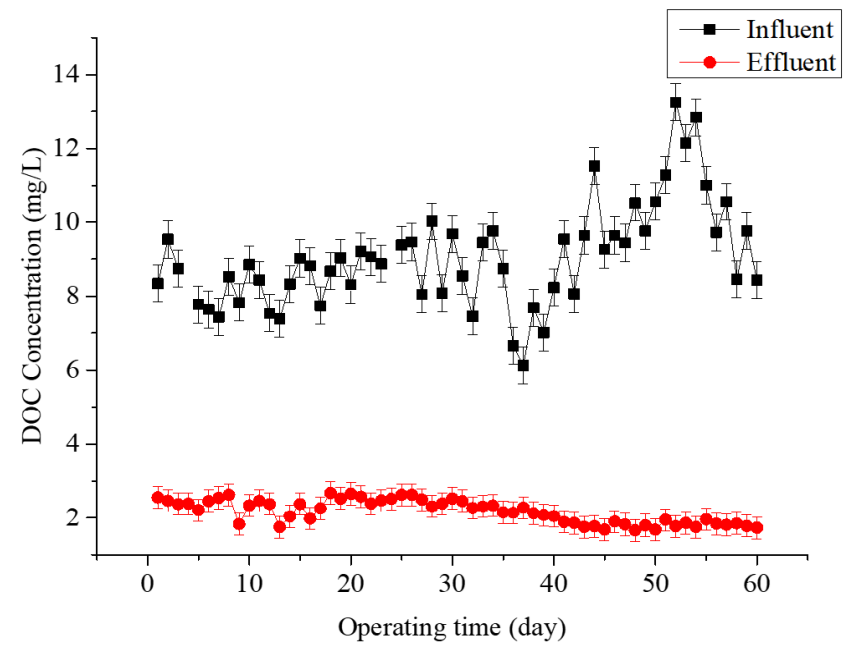

Fig. 4. DOC removal of the GDM unit during operation period.

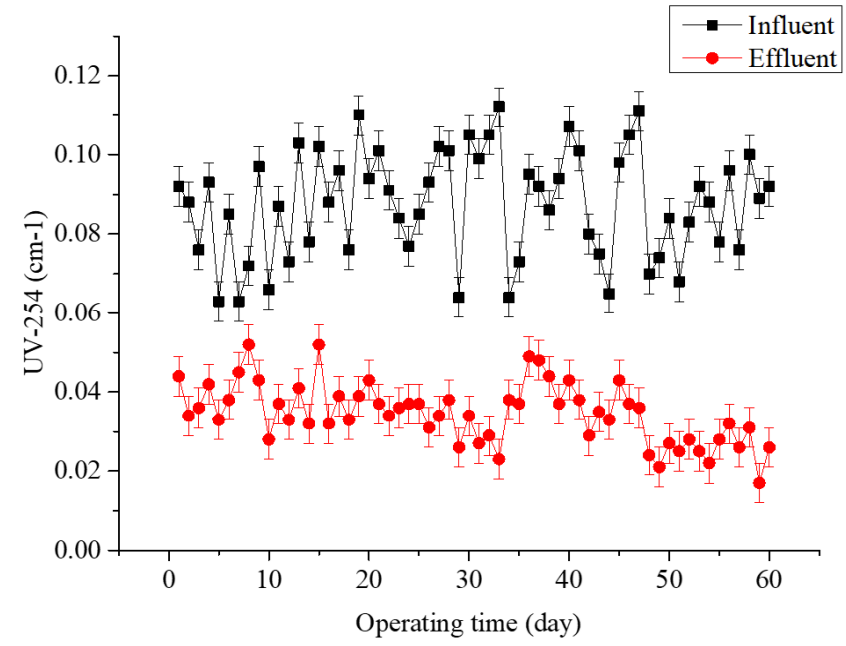

Fig. 5. UV254 removal of the GDM unit during operation period.

\subsection{Membrane Morphology}

The micrograph of microbial communities derived from the settlements of membrane surface were captured through a light microscope (Fig. 6(a)-(d)). As obvious, substantially eukaryotic microorganisms were observed on membrane surface. Under the microscope, these eukaryotic microorganisms are rod, or filamentous shapes, their sizes range from nearly one hundred micrometers to a few millimetres in length. This phenomenon may be attributed to the fact that in the GDM filtration reactor, a large number of microorganisms (consist of bacteria and eukaryotes) from the feed rainwater were retained due to membrane rejection, and the bacteria utilize the organic substances in the feed water for their growth and then form bio-film layers on the membrane surface. These bio-films may play important role in removing of pollutants especially degradable organic matter from rainwater. During current experiment, it is evident that there were abundant microorganisms gathered on the membrane surface and were growing during the long term filtration, making this GDM process evolved into a membrane bio-reactor (MBR), thus contributed to the degradation of organic substances. 

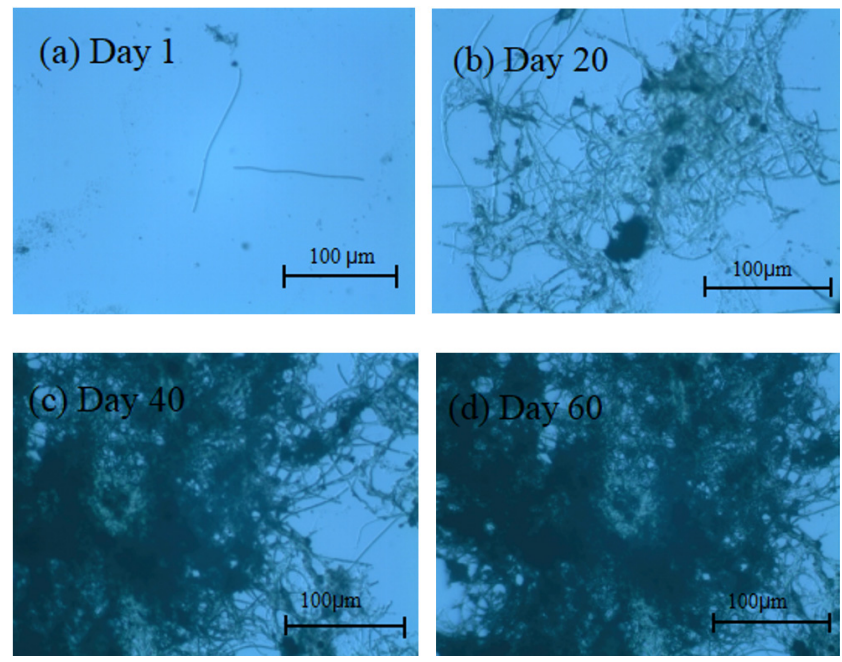

Fig. 6. Microscopic images of microorganisms derived from the membrane surface.

As can be seen from Fig. 6, the biomass in the later stages (i.e., by the end of 40th and 60th day, respectively, seen Fig. 6(c), (d)) were much higher than the early stages (Fig. 6(a), (b)). These observations were also consistent with the the aforementioned results (section 3.2) that the removal efficiency of ammonia nitrogen were improved in the later stage of the experiment.

\subsection{Flux Development Profiles}

The recorded flux development profiles of GDM reactors over a duration of 60 days are illustrated in Figure 7. For the planted roof rainwater filtration, the initial permeate fluxes of GDM reactor were desirable but it dropped rapidly with increasing running duration. After 10 days, the permeate flux of ceramic membrane declined to $60 \mathrm{~L} / \mathrm{m}^{2} \cdot \mathrm{h}$, approximately $36 \%$ of its initial level. It can be inferred that pore blocking may have occurred at the very beginning of operation, which caused permeate flux decline in the ceramic membrane GDM system.

Previous studies have documented that membrane fouling was primarily due to the deposition of soluble microbial products such as polysaccharides, proteins, and humic and fulvic substances onto the membrane surface or into membrane pores [28-30]. Therefore, it was expected that the permeate flux would further decline with the experiment prolonged since the cake layer has developed in the membrane surface without any backwashing and chemical cleaning. However, it was observed that the flux downward trend appeared to be moderate after 14 days, which was approximately equivalent to $45 \mathrm{~h}$ (it is noteworthy that the GDM reactor was operated at an intermittent mode of $2-4 \mathrm{~h}$ a day). The permeate flux of the GDM unit declined to a relative stable level that ranged between 22 and $47 \mathrm{~L} / \mathrm{m}^{2} \cdot \mathrm{h}$. Apparently, as shown in Fig. 7, the permeate flux profile of the current GDM reactor can be roughly categorized into two stages, the first stage was from the first day to 14th day, while the later stage spanned from the 14th day until to the end of the experiment.

Similar decline patterns have also been documented in some previous studies that employed seawater [31, 32], surface water [33],

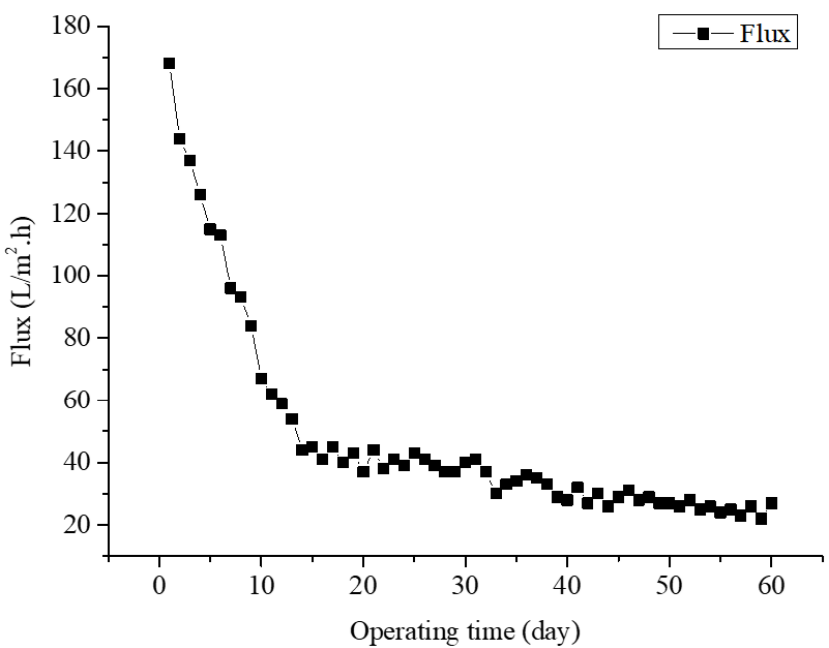

Fig. 7. Membrane flux decline during 60 days experiment.

grey water [34], and waste water as feed waters in micro-filtration systems. However, flat ceramic membrane with $0.1 \mu \mathrm{m}$ pore size shows much slower permeability decline, and the stabilized permeate fluxes were significant higher than those of previous studies documented, e.g, several studies have reported that the permeate fluxes of GDM filtration process were typically lower than $10 \mathrm{~L} / \mathrm{m}^{2} \cdot \mathrm{h}$, with most ranged from 3.6 to $14.9 \mathrm{~L} / \mathrm{m}^{2} \cdot \mathrm{h}$ [31-33, 35]. It is noted that the GDM system was not backwashed over an experimental duration of 60 days, although the flux can be recovered easily by hydraulic cleaning since Tang et al. have reported that more than $75 \%$ of membrane resistance comes from reversible fouling [29].

According to the findings by Peter et al. [33], the stabilization of flux was related to the development of heterogeneous structures in the bio-fouling layer on the membrane surface, and the level of stable permeate flux depended on the ATP and EPS contents of bio-fouling layer rather than the DOC concentration in the feed water. Therefore the high stabilized permeate fluxes in our experiment can only be partially attributed to the feed rainwater that contain fewer amounts of dissolved organic pollutants, even more importantly, the high fluxes may have mainly resulted from the hydrophilicity of the ceramic membrane, which lead to less accumulation of polysaccharides and proteins on the membrane surface, thus to lighten membrane fouling and clogging, then resulting in a higher permeate flux. In addition, the flat sheet membrane (compares with the hollow fiber membrane) provides a superior environment for the growth, predation, and movement of the eukaryotes or predators, which also contribute to resist the development of cake layer on membrane surface.

\section{Discussion}

In this study, a 60 days experiment was conducted to evaluate the performance of an innovative gravity driven ceramic membrane micro-filtration process for harvested rainwater treatment. Results shows that the treatment system reduced all the tested pollutants to below the limits of the Chinese Recycling Water Guideline (2014). Several parameters such as turbidity, TDS and bacteria even met 
the Chinese drinking water standard (2006), more importantly, without any backwashing throughout the entire experiment.

The performance of the GDM system in terms of the removal of several pollutants has been discussed in the previous sections. As pointed out elsewhere, the GDM process may exhibit excellent performance for bacteria and turbidity removals, but the removal efficiencies of organic matter and ammonia nitrogen were undesirable [36-39]. For example, Peng and Diamantis have reported that the micro-filtration were capable to remove majority of the suspended solids, colloidal particles and pathogens, but the removal rate of dissolved organic matters by alone micro-filtration process was generally lower than $20 \%$ [40,41].While Kus et al observed that a GDM process only contribute to $7 \%$ removal efficiency of DOC [42]. Similarly, Wu et al have recorded that a pilot GDM systems were able to remove almost all of the particles (i.e., turbidity), 94\% of viable cells, and most of TEP (41-85\%) [43]. However, Ding et al reveal that DOC (especially the organics containing unsaturated bonds or aromatic chromophores) of rainwater were not removed well (lower than 30\%) in GDM process [15]. Whereas in another study, Wu et al also found that GDM did not retain humics and low molecular weight neutrals during sea water treatment [32].

However, in current study, the average removal rate of DOC in GDM system was $76.9 \%$, which was significant higher than those of most previous researches documented. In addition, the removal of GDM system for other organic pollutants as well as ammonia nitrogen were also satisfying, through GDM filter, averagely $65.5 \%$ removal of CODcr, $42.6 \%$ removal of $\mathrm{NH}_{3}-\mathrm{N}$, and $61 \%$ removal of UV254 were achieved, respectively.

The relatively high efficiencies of the current GDM system in reducing dissolved organic matter and $\mathrm{NH}_{3}-\mathrm{N}$ could be attributed to two reasons. First, the ceramic membrane is a filter media with superior hydrophilicity. This characteristic allow the GDM system to run for a relative longer period without cleaning, and thereby it would favor various of microorganisms to accumulate and form a bio-film over the membrane surface, which consequently favours biodegradation in the GDM reactor, as a consequence, leading to a reduced concentration of dissolved organic matters retained in the treated rainwater. As found in our previous study, the ceramic membrane can integrates the coagulation, precipitation, adsorption, advanced oxidation, biological treatment and other processes, which can effectively remove organic matters [44]. It was noted that the membrane adopted in current experiment has a nominal pore size of $0.1 \mu \mathrm{m}$, therefore, theoretically the substances $<0.1$ $\mu \mathrm{m}$ cannot be rejected by the membrane. However, when the rainwater filtered through the membrane, these soluble substances could be adsorbed to or captured by the bio-film layer on the membrane, parts of organic fractions were assimilated and utilized as carbon source for microorganisms proliferation [11], thus enables a reduced DOM contents in effluent from GDM reactor. As can be seen from Fig. 2, Fig. 3, Fig. 4 and Fig. 5, the removal efficiency of GDM system for $\mathrm{NH}_{3}-\mathrm{N}$, CODcr, DOC and UV254 appeared to be slightly higher after 40 days operation, e.g. the effluent $\mathrm{NH}_{3}-\mathrm{N}$ concentrations were ranged from $2.53 \sim 4.77 \mathrm{mg} / \mathrm{L}$ in the first 30 days, then down to $1.65 \sim 3.22 \mathrm{mg} / \mathrm{L}$ from day 47 to the end (Fig. 4). This phenomenon may be as a result of the continuous operation of the GDM reactor, which could favor the attachment of nitrobacteria that possess longer growth period on the ceramic membrane surface, and consequently lead to nitrification taken place in the GDM reactor, thus benefit to the removal of ammonia nitrogen. Second, a proper water temperature (between $23.3^{\circ} \mathrm{C}$ and $28.2^{\circ} \mathrm{C}$ ) also promoted the degradation of organic compounds. Previous study shows that the activity of microorganism reached maximum at a temperature range of 25 to $35^{\circ} \mathrm{C}$, while the activities of microorganism and the hydrolysis rate may decline when the temperature drops [45].

The observation that the increase in organic removal was related to the microbial biodegradation is also agreed with the findings in previous studies [30, 46]. The cake layer formed on the surface of membrane has been reported to lead to a quality improvement of drinking water filtration system [47, 48]. As pointed out by Vincenzo et al. [46] (2013), in the filtration system of surface water, due to long-term operation of the filter, microorganism such as bacteria, protozoa and metazoa have opportunities to accumulate on the membrane surface, thus to form a biofilm with bioactivity, resulting in the biodegradation of soluble organic constituents.

In addition to the aforementioned aspects, the higher organic matter removal rate may be linked to the longer hydraulic retention time of the GDM reactor, since the HRT in the later stage was increased due to the decline of permeate flux. Prior studies have noted that longer hydraulic retention time would favour the growth and proliferation of microorganisms on membrane surface, especially eukaryotes, which could resulted in a bio-film with higher biomass and greater diversity [43], whereas the HRT of the GDM reactor is mainly determined by the size of GDM reactor (HRT, is calculated through dividing reactor volume by flux rate). These findings hinting that the reactor dimension is an important factor determining both organic degradation and development of the bio-film on the membrane surface of the GDM filter tank. Therefore, Follow-up investigations are planned to optimize this parameter in order to achieve higher removal efficiency with lower maintenance.

In terms of permeate flux, the stabilized flux was at 22 45 $\mathrm{L} / \mathrm{m}^{2} \cdot \mathrm{h}$ over 60 days experiment, which was significantly higher than that of previous study documented, e.g., Bing Wu (2017) have reported that stabilized permeate flux of 16.3 to $18.6 \mathrm{~L} / \mathrm{m}^{2} \mathrm{~h}$ were achieved at a hydrostatic pressure of 200 mbar by hollow fibre membrane reactor after two months operation [43]. This is possibly attributed to the fact that, compared to the hollow fiber membrane, the flat sheet membrane module provides more space for the predation and movement of some eukaryotes that were growing and propagating in the GDM reactor, since the movement and predation behaviour of eukaryotic organisms have been reported to produce the porous, sponge-like structures of biofilm, which benefits to the improvement of permeate flux [43].

Although the current study is specific to study site, however, this paper presents an insight on potential advantages of GDM system using flat ceramic membrane for rainwater treatment and such study will motivate others to conduct similar investigations in elsewhere.

\section{Conclusions}

The ceramic membrane was employed in a GDM system to treat harvested rainwater at Lab-scale. Results showed that this process 
presented excellent performance in term of pollutants removing and permeate flux. The average removal rate of turbidity, TDS, CODcr, $\mathrm{NH}_{3}-\mathrm{N}$, DOC, UV254, Coliforms and E.coli by the GDM system was $92.2 \%, 91.9 \%, 65.5 \%, 42.6 \%, 76.9 \%, 61 \%, 96.9 \%$ and $95.5 \%$, respectively, with all surveyed parameters meeting the standards for non-potable purpose. The permeate flux of the GDM system dropped rapidly during the initial 14 days, and then tended to be stabilized at $22 \sim 45 \mathrm{~L} / \mathrm{m}^{2} \cdot \mathrm{h}$ without cleaning over two months of operation. The results obtained implying that this innovative GDM process is prospective to offer an opportunity to supply potable water through regenerating rainwater in decentralized residences in an efficient, simple, and energy-free way.

\section{Acknowledgement}

This study was funded by the Key Scientific Research Project of Guangdong University (Characteristic Innovation). We wish to thank the staff of laboratory, ZhongKai University of Agriculture and Engineering, for the convenience of this experiment. We are thankful to the anonymous reviewers and the editor for their constructive comments and suggestions on the manuscript.

\section{Author Contributions}

C.S. (Lecturer) conceived the research goals, designed the methodology, conducted all the experiments and wrote the manuscript. S.H. (Associate Professor) analyzed experimental data and revised the manuscript. C.Q. (Associate Professor) revised the manuscript.

\section{References}

1. Bixio D, Thoeye C, De KJ, et al. Wastewater reuse in Europe. Desalination 2006;187:89-101.

2. Abbasi T, Abbasi SA. Sources of pollution in rooftop rainwater harvesting systems and their control. Crit. Rev. Environ. Sci. Technol. 2011;41(23):2097-2167.

3. Ghimire SR, Watkins Jr DW, Li K. Life cycle cost assessment of a rain water harvesting system for toilet flushing. Water Sci. Technol. Water Supply. 2012;12:309-320.

4. Gurung TR, Sharma A. Communal rainwater tank systems design and economies of scale. J. Clean. Prod. 2014;67:26-36.

5. Siems R, Sahin O. Energy intensity of residential rainwater tank systems: exploring the economic and environmental impacts. J. Clean. Prod.2016;113:251-262.

6. Wang R, Zimmerman JB. Economic and environmental assessment of office building rainwater harvesting systems in various U.S. cities. Environ. Sci. Technol. 2015;49:1768-1778.

7. Liaw $\mathrm{CH}$, Tsai YL. Optimum storage volume of roof top rain water harvesting systems for domestic use. J. Am. Water Reso. 2004;40:901-912.

8. Hwang AHS, Valeo C, Draper D. Public perceptions and attitudes toward stormwater recycling for irrigation. Can. Water Resour. J. 2006;31:185-196.

9. Ree HK, Sangho L, Jong K. Application of a metal membrane for rainwater utilization: filtration characteristics and membrane fouling. Desalinnation 2005;177:121-132.

10. Leong JYC, Oh KS, Poh PE, Chong MN. Prospects of hybrid rainwatergreywater decentralised system for water recycling and reuse: a review. J. Clean. Prod. 2017;142:3014-3027.

11. Bing W, Genevieve QY, Tzyy HC. Recycling rainwater by submerged gravity driven membrane (GDM) reactors: Effect of hydraulic retention time and periodic backwash. Sci. Total Environ. 2019;654:10-18.

12. Bing W, Tino C, Hwee ST, Florian H, Anthony GF. Improved performance of gravity driven membrane filtration for seawater pretreatment: Implications of membrane module configuration. Water Res. 2017;114:59-68.

13. Ding A, Wang JL, Lin DC, et al. Effects of GAC layer on the performance of gravity driven membrane filtration (GDM) system for rainwater recycling. Chemosphere 2018;191:253-261.

14. Kus B, Kandasamy J, Vigneswaran S, Shon HK, Moody G. Gravity driven membrane filtration system to improve the water quality in rainwater tanks. Water Sci. Technol. Water Supply. 2013;13 (2):479-485

15. Ding A, Jinlong W, Dachao L, et al. A low pressure gravity driven membrane filtration (GDM) system for rainwater recycling: Flux stabilization and removal performance. Chemosphere 2017;172:21-28.

16. Dikshhant S, Liz TE, Robert CA. Comparative assessment of ceramsite media for drinking water biofiltration. Water Res. 2018;128:1-9.

17. Junliang L, Qin W, Junjing L. Water treatment filler and filter material. Beijing: Chemical Industry Press;2010. p. 1-194.

18. Hasan MM, Nakajima J. Operational factors in membrane bioreactors using a simple ceramsite filter. J. Water Environ. Technol. 2014;12:65-75.

19. Hasan MM, Shafiquzzaman M, Nakajima J, Ahmed AKT, Azam MS. Application of a low cost ceramsite filter to a membrane bioreactor for greywater treatment. Water Environ. Res. 2015;87:233-241.

20. Bendick JA, Modise CM, Miller CJ, Neufeld RD, Vidic RD. Application of cross-flow micro-filtration for the treatment of combined sewer overflow wastewater. J. Environ. Eng. ASCE. 2004;130:1442-1449.

21. Ding A, Jinlong W, Dachao L, et al. A low pressure gravity driven membrane filtration (GDM) system for rainwater recycling: flux stabilization and removal performance. Chemosphere 2017;172:21-28.

22. Kus B, Kandasamy J, Vigneswaran S, Shon H, Moody G. Two stage filtration for stormwater treatment: a pilot scale study. Desalin. Water Treat.2012;45:361-369.

23. State Environmental Protection Administration. Water and Wastewater Monitoring and Analysis Methods. Beijing: China Environmental Science Press; 2002. p.722-784.

24. Huaiyu Z, Shuyuan L, Wenjin Y, Xiaoping Z, Guizhen W. Chinese Recycling Water Guidelines. Beijing: China Standards Press; 2003. p. 2-8.

25. Yinlong J, Xueli E, Changjie C, Xiping C, Lan Z. Chinese Drinking Water Guidelines. Beijing: China Standards Press; 2006. p.3-6.

26. Minju L, Mikyeong K, Yonghwan K, Mooyoung H. Consideration of rainwater quality parameters for drinking purposes: A case 
study in rural Vietnam. J. Environ. Manag. 2017;200:400-406.

27. Gary LA, Raymond AS, James B, David P, Lo T. Molecular Size Distributions of Dissolved Organic Matter. J. Am. Water Works Ass. 1992;84:67-75.

28. Lin $\mathrm{H}$, Zhang $\mathrm{M}$, Wang $\mathrm{F}$, et al. A critical review of extracellular polymeric substances (EPSs) in membrane bioreactors:characteristics, roles in membrane fouling and control strategies. J. Membr. Sci. 2014;460:110-125.

29. Tang S, Zhang Z, Zhang X. Coupling in-situ ozonation with ferric chloride addition for ceramic ultrafiltration membrane fouling mitigation in wastewater treatment: quantitative fouling analysis. J. Membr. Sci. 2018;555:307-317.

30. Zhu H, Wen X, Huang X. Membrane organic fouling and the effect of preozonation in micro-filtration of secondary effluent organic matter. J. Membr. Sci. 2010;352:213-221.

31. Akhondi E, Wu B, Sun SY, et al. Gravity driven membrane filtration as pretreatment for seawater reverse osmosis: linking biofouling layer morphology with flux stabilization. Water Res .2015;70:158-173.

32. Bing W, Florian H, Ebrahim A, et al. Optimization of gravity driven membrane (GDM) filtration process for seawater pretreatment. Water Res. 2016;93:133-140.

33. Peter-Varbanets M, Hammes F, Vital M, Pronk W. Stabilization of flux during dead-end ultra-low pressure ultrafiltration. Water Res. 2010;44:3607-3616.

34. Ding A, Heng L, Guibai Li, et al. Impact of aeration shear stress on permeate flux and fouling layer properties in a low pressure membrane bioreactor for the treatment of greywater. J. Membr. Sci. 2016;510:382-390.

35. Derlon N, Peter-Varbanets M, Scheidegger A, Pronk W, Morgenroth E. Predation influences the structure of biofilm developed on ultrafiltration membranes. Water Res. 2012;46: 3323-3333.

36. Bendick JA, Miller CJ, Kindle BJ, Shan H, Vidic RD, Neufeld RD. Pilotscale demonstration of cross-flow ceramic membrane micro-filtration for treatment of combined and sanitary sewer overflows. J. Environ. Eng. ASCE. 2005;131:1532-1539.

37. Judd SJ, Till SW. Bacterial rejection in crossflow micro-filtration of sewage. Desalination 2000;127:251-260.
38. Sayed S, Tarek S, Dijkstra I, Moerman C.Optimum operation conditions of direct capillary nanofiltration for wastewater treatment. Desalination 2006;214:215-226.

39. Schafer AI, Nghiem LD, Oschmann N. Bisphenol A retention in the direct ultrafiltration of greywater. J. Membr. Sci. 2006;283: 233-243.

40. Ting P, Zaifeng S, Qiang L, Xianghui W, Cuiqiong M. Studies on PVC ultrafiltration membrane for treating municipal sewage and control of membrane fouling. Membr. Sci. Technol. 2015;35(2):75-81.

41. Diamantis VI, Antoniou I, Melidis P, Aivasidis A. Direct Membrane Filtration of Sewage Using Aerated Flat-sheet Membrane. Proceedings of the 11 th International Conference on Environmental Science and Technology; 3-5April 2009. Greece. p.230-237.

42. Kus B, Kandasamy J, Vigneswaran S, Shon HK, Moody G. Gravity driven membrane filtration system to improve the water quality in rainwater tanks. Water Sci. Technol. Water Supply. 2013;13(2):479-485.

43. Bing W, Suwarno SR, Tan HS, et al. Gravity driven micro-filtration pretreatment for reverse osmosis (RO) seawater desalination: microbial community characterization and RO performance. Desalination 2017;418:1-8.

44. Shiguang C, Hongwei S, Chong L, Xianrong Z, Zhihong W, Jongji X. Technology prospects of membrane antifouling in wastewater treatment. Environ. Sci. Technol. 2019;42:143-153.

45. Lihong C, Changfa X, Quan Q, Hailiang L, Mingxing C. Membrane fouling and dealing with domestic sewage in MBR of homogeneous enhanced PMIA hollow fiber membranes. CIESC J. 2016;67:3954-3964.

46. Vincenzo N, Davide S, Vincenzo B. Enhanced drinking water supply through harvested rainwater treatment. J. Hydrol. 2013;498:287-291.

47. Dikshhant S, Liz T, Robert C. Comparative assessment of ceramic media for drinking water biofiltration. Water Res. 2018;128:1-9.

48. Lautenschlager K, Hwang C, Ling F, et al. Abundance and composition of indigenous bacterial communities in a multi-step biofiltration-based drinking water treatment plant. Water Res. 2014;62:40-52. 